\title{
Mutations in the opioid growth factor receptor in human cancers alter receptor function
}

\author{
NANCY P. KREN, IAN S. ZAGON and PATRICIA J. McLAUGHLIN
}

Department of Neural and Behavioral Sciences, Pennsylvania State University College of Medicine, Hershey, PA 17033, USA

Received March 24, 2015; Accepted May 15, 2015

DOI: $10.3892 /$ ijmm.2015.2221

\begin{abstract}
The opioid growth factor (OGF)-OGF receptor (OGFr) axis is present and tonically active in animal and human cancer cell lines and tumors. The OGF-OGFr pathway tonically mediates cell replication in cancer, with OGF serving as an autocrine-produced inhibitory pentapeptide. The inhibitory effect of OGF on cancer cell replication requires the binding of OGF to OGFr and its trafficking into the nucleus, where it upregulates inhibitory kinase expression, thus suppressing the cell cycle. OGF has been reported to markedly inhibit the growth of human cancer cells transplanted into nude mice, and to enhance the therapeutic effects of agents, such as paclitaxel and gemcitabine. At the time that this study commenced, there were 13 missense mutations identified in OGFr that had been curated in the Catalogue of Somatic Mutations in Cancer (COSMIC) database. Little is known about any mutations identified in OGFr or how mutated OGFr may alter the inhibitory activity of OGF. In this study, two mutations identified in cancer samples, S378I and $\mathrm{R} 444 \mathrm{H}$, were characterized with respect to how they modified OGFr trafficking into the nucleus and changed the functional attributes of DNA synthesis. R444H demonstrated a significant decrease in the nuclear/cytoplasmic ratio, while S378I showed no change. Both mutations demonstrated a loss of response to OGF and the long-acting opioid antagonist, naltrexone (NTX), while only R444H showed a loss of inhibition in the 5-bromo-2'-deoxyuridine (BrdU) assay. These data demonstrate that an intact OGFr is required for a full
\end{abstract}

Correspondence to: Dr Patricia J. McLaughlin, Department of Neural and Behavioral Sciences, Pennsylvania State University College of Medicine, 500 University Drive, MC H109, Hershey, PA 17033-0850, USA

E-mail:pxm9@psu.edu

Abbreviations: OGF, opioid growth factor; OGFr, opioid growth factor receptor; BrdU, 5-bromo-2'-deoxyuridine; NTX, naltrexone; PBS, phosphate-buffered saline; DAPI, 4',6-diamidino-2-phenylindole

Key words: human cancer, opioid growth factor receptor, opioid growth factor, DNA synthesis response to biotherapy with OGF, and that it is important to characterize potential mutations in neoplasia which could affect therapeutic responsiveness.

\section{Introduction}

The opioid growth factor (OGF)-OGF receptor (OGFr) axis has been characterized in animal and human cancer cell lines $(1,2)$, as well as in animal and human tumors (3). The OGFr-OGF axis is a tonically active pathway, and the knockdown of the receptor with small interfering RNA (siRNA) technology increases cell proliferation $(1,4-6)$. Treatment with OGF or low-dose naltrexone (LDN) in cell culture or in mouse models has been shown to significantly decrease cell proliferation (7). Additionally, it has been demonstrated that OGF and LDN function in combination with standard chemotherapeutic agents to suppress tumor growth (7). Using several human breast cancer cell lines, OGF has been shown to inhibit cell replication alone or in combination with paclitaxel (4). Moreover, lower concentrations of paclitaxel, which are known to be cytotoxic, may be used in combination with OGF with similar therapeutic results (4). In order to better understand the function of the OGF-OGFr regulatory axis, mutations identified through the Catalogue of Somatic Mutations in Cancer (COSMIC) $(8,9)$ database were selected for their location and characterized. At the present time, to the best of our knowledge, there is no information correlating function and receptor mutation. It is important to identify potential mutations that alter the function of the axis, specifically the role that OGF plays in the inhibition of cell replication. This information would facilitate personalized medical treatment by enabling the identification of cancer responsive to treatment with OGF and LDN. Mutation data were obtained from the Sanger Institute's COSMIC database (http://cancer.sanger.ac.uk/cosmic) (9). Thirteen mutations in OGFr are listed in the COSMIC $(8,9)$ database. Fig. 1 demonstrates the identified mutations and their location in relation to the known functional regions of OGFr. The functional domains of OGFr have not yet been completely defined; however, of the identified mutations, S378I is a putative phosphorylation site, and residue R444H falls within the potential ligand-binding domain. For these reasons, we chose to explore the functional changes associated with the mutation S378I, identified in a kidney cancer sample, and R444H, identified in a lung cancer sample. 


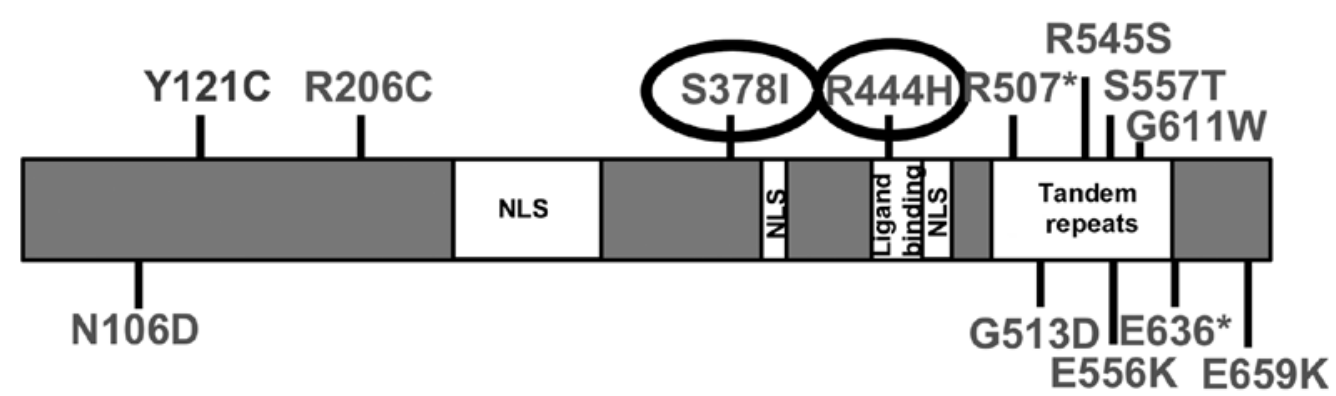

Figure 1. Generalized schematic showing the 13 mutations identified in the COSMIC database at the start of this study and their location with respect to known functional regions of the opioid growth factor receptor (OGFr). The two black circles indicate the mutations that are characterized. NLS, nuclear localization signal.

\section{Materials and methods}

Cell culture. Transformed African green monkey kidney cells, COS-7 cells, were purchased from the American Type Culture Collection (ATCC, Manassas, VA, USA) and cultured in Dulbecco's modified Eagle's medium supplemented with $10 \%$ fetal calf serum and antibiotics $(5,000 \mathrm{U} / \mathrm{ml}$ penicillin and $5 \mathrm{mg} / \mathrm{ml}$ streptomycin). The cells were grown in a humidified atmosphere of $5 \% \mathrm{CO}_{2} / 95 \%$ air at $37^{\circ} \mathrm{C}$.

Plasmids. OGFr-enhanced green fluorescent protein (EGFP) was previously generated (10) by cloning OGFr into the pEGFP-N1 plasmid using EcoRI and SalI. A QuikChange Site-Directed Mutagenesis kit (200518; Agilent Technologies, Santa Clara, CA, USA) was utilized to generate the mutations in OGFr-EGFP using the following primers: S378I forward, 5'-ggaagataggccagagccettaatccccaaagaga-3' and reverse, 5'-ctctc tttggggattaagggetctggectatcttcc-3'; and R444H forward, 5'-gcag ccctgccaccaaccctgg-3' and reverse, 5'-ccaggggttggtggcaggg ctgc-3'. Mutations were confirmed by sequencing. All transfections were performed in 6-well plates with $5 \mu \mathrm{g}$ of DNA and $5 \mu \mathrm{l}$ of Lipofectamine 2000/well for $4 \mathrm{~h}$. After $4 \mathrm{~h}$, the medium was removed and replaced with fresh complete, medium.

Localization studies. The cells $\left(2 \times 10^{5}\right)$ were seeded on glass coverslips and allowed to attach for $24 \mathrm{~h}$ prior to transfection. The cells were transfected with the empty vector (EGFP) control, wild-type OGFr (OGFr-EGFP) or the mutated OGFr plasmids (S378I-EGFP or R444H-EGFP). At 18-24 h post-transfection, the cells were washed in phosphate-buffered saline (PBS), counterstained with Hoechst 33342 (H3570; Molecular Probes/Life Technologies, Carlsbad, CA, USA) and fixed in 4\% paraformaldehyde ( $\mathrm{pH}$ 7.4) for $30 \mathrm{~min}$ at room temperature. The coverslips were imaged using an Olympus IX-81 epifluorescence microscope at $\mathrm{x} 40$ magnification. At least 30 images were collected per group. The images were exported as .tiff files and analyzed using CellProfiler to quantify the nuclear/cytoplasmic ratio. Images were converted to gray scale and split by channel. Nuclei were identified as primary objects by intensity of Hoechst 33342 staining. Based on the identified primary objects, the intensity of EGFP in the nucleus was analyzed and used to set a threshold for EGFP-positive cells. For the cells that were identified as positive, a fixed cytoplasm of 25 pixels around the nucleus was measured for EGFP intensity. The nuclear to cytoplasmic ratio was found by dividing the average EGFP intensity of the nucleus by the average EGFP intensity of the defined cytoplasm.
Growth curves. The COS-7 cells were seeded at $2 \times 10^{5}$ cells per well in 6-well plates and allowed to attach for $24 \mathrm{~h}$ prior to transfection with wild-type, or mutant OGFr, or the empty control vector for comparison. The cells were treated with sterile water, OGF (M6638; Sigma-Aldrich, St. Louis, MO, USA) or naltrexone (N3136; Sigma-Aldrich). The drugs were dissolved in sterile water and the concentrations represent the final dilution. Twenty-four hours after transfection (as described above), the cells were harvested by trypsinization, counted and seeded at $2.5 \times 10^{4}$ cells/well in 24-well plates. The cells were placed under selection for neomycin resistance using G418 (Geneticin; Invitrogen Life Technologies). The cells were counted every $24 \mathrm{~h}$ for $120 \mathrm{~h}$. At least 3 wells per group were counted for each time point; the experiments were conducted at least twice.

5-Bromo-2'-deoxyuridine (BrdU) assay. To examine the effects of OGFr mutation on DNA synthesis, BrdU assays were conducted. The cells $\left(2 \times 10^{5}\right)$ were seeded on coverslips and allowed to attach for $24 \mathrm{~h}$, after which time they were transfected. At $15-24 \mathrm{~h}$ posttransfection, the cells were pulsed with $30 \mu \mathrm{M}$ BrdU for $3 \mathrm{~h}$. The cells were then washed in PBS, and fixed in acetone:methanol (1:1 vol:vol) for $20 \mathrm{~min}$ at $-20^{\circ} \mathrm{C}$. The coverslips were stained with Alexa Fluor 488 anti-GFP antibody at 1:200 (A21311) and Alexa Fluor 596 anti-BrdU antibody at 1:200 (B35132), and counterstained with DAPI (D1306) (all from Life Technologies). The coverslips were imaged using an Olympus IX-81 epifluorescence microscope, and at least 30 images were collected per group. The number of dual-labeled cells (positive for BrdU and GFP) was divided by the total number of GFP-positive cells to calculate the BrdU index.

Data analyses. All data (nuclear/cytoplasmic ratios, cell numbers and BrdU indexes) were compared using one-way analysis of variance (ANOVA) with Newman-Keuls post hoc tests. A P-value $<0.05$ was considered to indicate a statistically signficant difference.

\section{Results}

The COSMIC database was examined for mutations identified in OGFr. There were 13 mutations identified in various types of cancer (Fig. 1). Of these 13 mutations, S378I and R444H were selected for further characterization due to their potential roles in cell cycle regulation. S3781 is a putative phosphorylation site that has been identified in a number of large phosphoproteomic studies (11-17), while R444H is located within the 
A

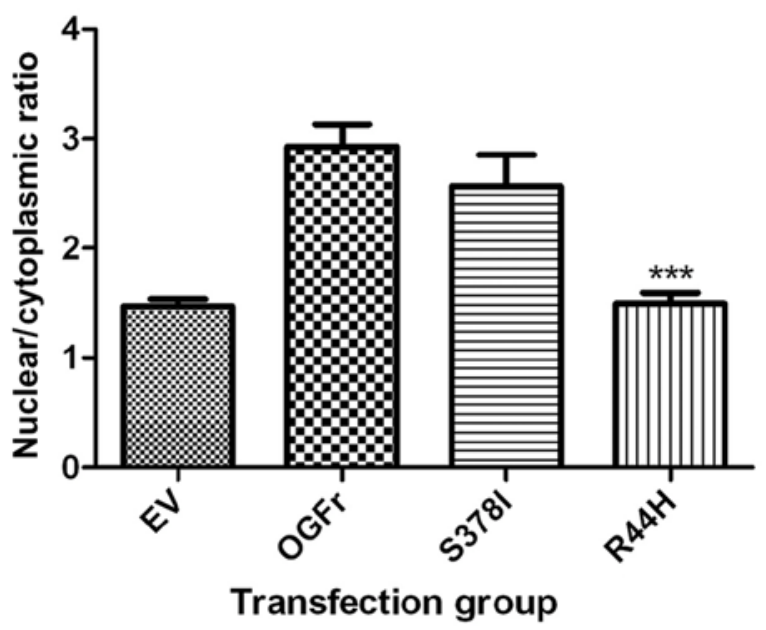

B

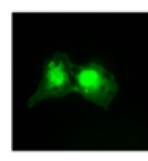

EV

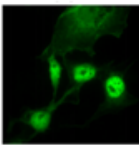

OGFr

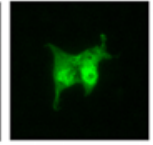

S378I

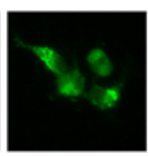

R444H

Figure 2. (A) Nuclear/cytoplasmic ratio for each of the mutations compared to wild-type opioid growth factor receptor (OGFr); ${ }^{* * *} \mathrm{P} \leq 0.001$. (B) Representative images of each of the mutations; original magnification, $\mathrm{x} 60 . \mathrm{EV}$, empty vector.

purported ligand-binding domain (unpublished data). Our hypothesis was that these mutations would significantly alter the function of the receptor if either region or residue played a critical role in the function of OGFr. In order to examine this hypothesis, site-directed mutagenesis was utilized to modify wild-type OGFr with each mutation. The mutated plasmids were then transfected into COS-7 cells. The localization of each mutant was then compared to the localization of wild-type OGFr (Fig. 2). The R444H mutation resulted in a significant decrease in nuclear localization, while S378I showed no significant change in localization, as demonstrated in Fig. $2 \mathrm{~B}$ in the representative images of each group. If $\mathrm{R} 444 \mathrm{H}$ is located within the ligand-binding region, it would be expected to alter ligand binding, and this could result in decreased nuclear localization.

In order to examine the effects of mutated OGFr on cell growth, the COS-7 cells were transiently transfected with mutant plasmids. To inhibit the growth of untransfected cells, cells were placed under G418 selection. The transfected cells were treated with sterile water, OGF $\left(10^{-6} \mathrm{M}\right)$ or naltexrone (NTX; $\left.10^{-6} \mathrm{M}\right)$. The overexpression of wild-type OGFr responded to OGF and NTX by decreasing and increasing cell replication, respectively; whereas the cells transfected with mutations for S378I and R444H demonstrated a loss of response to OGF or NTX, indicating that the mutated OGFr lost the ability to be modulated by the agonist (OGF), as well as by the opioid receptor antagonist (NTX) (Fig. 3). In order to further examine the effects of mutated OGFr on cell proliferation, DNA synthesis was measured using a BrdU assay. The overexpression of OGFr, as well as the S378I mutation, significantly decreased BrdU incorporation; whereas the overexpression of $\mathrm{R} 444 \mathrm{H}$ had no significant effect on the incorporation of BrdU (Fig. 4). These results indicate that the growth activity attributed to the OGF interaction with OGFr
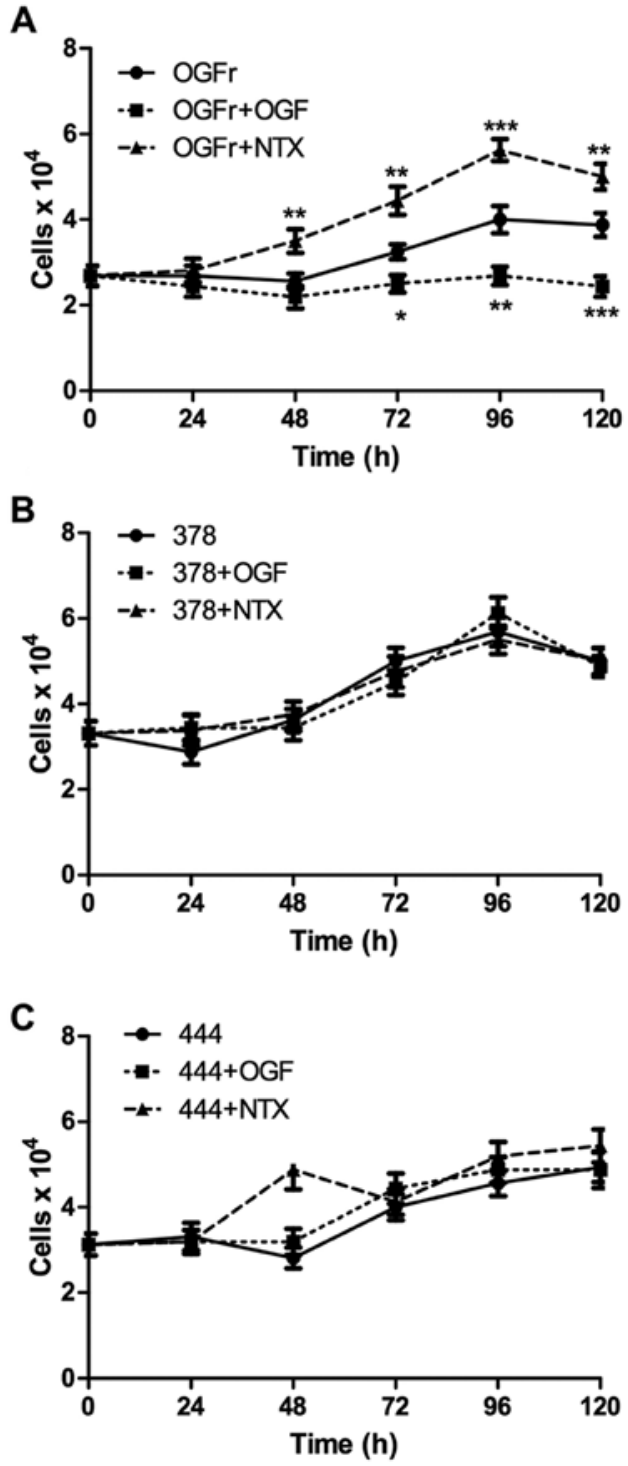

Figure 3. Growth curves demonstrating the loss of response to opioid growth factor (OGF) and naltrexone (NTX). Cells transfected with (A) OGF receptor (OGFr)-enhanced green fluorescent protein (EGFP), (B) S378I, or (C) R444H were seeded and treated with OGF $\left(10^{-6} \mathrm{M}\right), \operatorname{NTX}\left(10^{-6} \mathrm{M}\right)$ or sterile water and counted every $24 \mathrm{~h}$ for $120 \mathrm{~h}$. ${ }^{*} \mathrm{P} \leq 0.05,{ }^{* *} \mathrm{P} \leq 0.01,{ }^{* * *} \mathrm{P} \leq 0.001$.

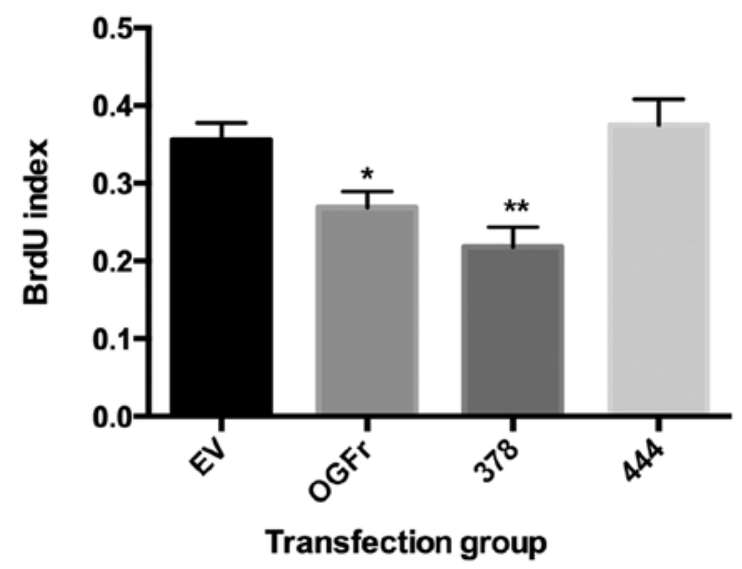

Figure 4. 5-Bromo-2'-deoxyuridine (BrdU) assay demonstrating the inhibitory effects of the overexpression of opioid growth factor receptor (OGFr) or S378I and the loss of inhibition in cells transfected with $\mathrm{R} 444 \mathrm{H} .{ }^{*} \mathrm{P} \leq 0.05,{ }^{* *} \mathrm{P} \leq 0.01$ $\mathrm{EV}$, empty vector. 
is altered by both mutations, S378I and R444H; moreover, the blockade by NTX resulting in enhanced cell replication is diminished by both mutations. Furthermore, the OGFr mutation $\mathrm{R} 444 \mathrm{H}$ alters the localization of the receptor to the nucleus.

\section{Discussion}

The OGF-OGFr axis has been characterized and identified as a determinant in a variety of human cancers arising from all germ layer derivations (1). To further characterize the axis with regard to cancer, the COSMIC $(8,9)$ database was surveyed to identify mutations reported in human cancer samples. Of the 13 identified missense mutations which had been identified at the time, two were located in regions of interest. S378I is a putative phosphorylation site that has been identified in numerous large phosphoproteomic studies (11-15,17,18). S378I has been reported to be exclusively phosphorylated in the cytoplasm of HeLa cells (15) and differentially phosphorylated throughout the cell cycle $(12,16)$. It has also been identified as a phosphorylated residue in additional cell lines, such as Jurkat T cell leukemia cells (11) and MV4-11 leukemia cells (14), as well as in normal liver tissue (13). S378I has also been found as a phosphorylated residue in two mouse studies which examined melanoma (17) and normal brain tissue (18). The number of sites this residue has been identified as being phosphorylated, as well as the differential phosphorylation between the nucleus and the cytoplasm and throughout the cell cycle, reinforces its potential importance. Furthermore, in the present study, mutations were characterized in an asynchronous population of cells. At least for the S378I mutation, the results may be exacerbated in a synchronized population of cells. Further investigations are warranted.

$\mathrm{R} 444 \mathrm{H}$ was characterized as it is localized within a region identified as a potential ligand-binding domain (unpublished data). If this region is verified as a ligand binding domain, then a residue substitution may alter ligand binding, as well as the downstream function of the receptor.

Both mutations were characterized for changes in localization. R444H showed a significant decrease in nuclear localization, while S378I showed no significant change in localization. It has previously been demonstrated that the function of the receptor is dependent on its nuclear localization (10), indicating that $\mathrm{R} 444 \mathrm{H}$ has the potential to significantly alter the function of the receptor. The function of both mutations was characterized using growth curves. The cells were selected such that only cells which had plasmids were capable of replicating. Cells with either mutation had an inhibited response to excess ligand, OGF or the receptor antagonist, NTX, suggesting a loss of regulation. The mutations were also characterized with regard to the overall function of the receptor. It has been previously demonstrated that the overexpression of OGFr significantly decreases BrdU incorporation (10). S378I showed no significant change in BrdU incorporation. Again this may be due to the asynchronous population of cells. $\mathrm{R} 444 \mathrm{H}$ demonstrated a complete loss of growth inhibition, indicating that the receptor had lost its function. These experiments indicate that $\mathrm{R} 444 \mathrm{H}$ renders the receptor inactive and that S378I may alter the response to OGF and NTX. These functions are critical for modulating the OGF-OGFr axis in cancer therapy. These data demonstrate that cancer mutations in OGFr can inhibit receptor function, and thus extend our knowledge of the role played by the OGF-OGFr pathway in mediating cancer growth.

Although only these two mutations were characterized for the reasons explained above, important information may be obtained by further characterization of these mutations, as well as others that have been identified. At the time this study commenced, 13 missense mutations had been identified in the database; however, the database has now been updated to include 111 mutations, 49 of which are missense (9). The increase in the number of mutations suggests that OGFr does in fact play a critical role as a biological regulatory pathway. In the updated catalog of mutations, many appear to occur in the tandem repeat region of OGFr, suggesting that this region may have functional importance. However, at this time, the function of the tandem repeats is unknown. Further mutation analyses are warranted for the tandem repeat region, as well as other regions of the protein.

\section{Acknowledgements}

This study was supported in part by funding from the Paul K. and Anna M. Shockey Foundation.

\section{References}

1. Zagon IS, Donahue RN and McLaughlin PJ: Opioid growth factor-opioid growth factor receptor axis is a physiological determinant of cell proliferation in diverse human cancers. Am J Physiol Regul Integr Comp Physiol 297: R1154-R1161, 2009.

2. Kren NP, Zagon IS and McLaughlin PJ: Modulation of the opioid growth factor receptor alters the proliferation and progression of cancer. Trends Cancer Res 9:53-64, 2013.

3. Fanning J, Hossler CA, Kesterson JP, Donahue RN, McLaughlin PJ and Zagon IS: Expression of the opioid growth factor-opioid growth factor receptor axis in human ovarian cancer. Gynecol Oncol 124: 319-324, 2012.

4. Zagon IS, Porterfield NK and McLaughlin PJ: Opioid growth factor-opioid growth factor receptor axis inhibits proliferation of triple negative breast cancer. Exp Biol Med (Maywood) 238: 589-599, 2013.

5. Donahue RN, McLaughlin PJ and Zagon IS: Cell proliferation of human ovarian cancer is regulated by the opioid growth factor-opioid growth factor receptor axis. Am J Physiol Regul Integr Comp Physiol 296: R1716-R1725, 2009.

6. Campbell AM, Zagon IS and McLaughlin PJ: Astrocyte proliferation is regulated by the OGF-OGFr axis in vitro and in experimental autoimmune encephalomyelitis. Brain Res Bull 90: 43-51, 2013.

7. Donahue RN, McLaughlin PJ and Zagon IS: Low-dose naltrexone suppresses ovarian cancer and exhibits enhanced inhibition in combination with cisplatin. Exp Biol Med (Maywood) 236: 883-895, 2011.

8. Forbes SA, Bindal N, Bamford S, Cole C, Kok CY, Beare D, Jia M, Shepherd R, Leung K, Menzies A, et al: COSMIC: mining complete cancer genomes in the Catalogue of Somatic Mutations in Cancer. Nucleic Acids Res 39: D945-D950, 2011.

9. Bamford S, Dawson E, Forbes S, Clements J, Pettett R, Dogan A Flanagan A, Teague J, Futreal PA, Stratton MR and Wooster R: The COSMIC (Catalogue of Somatic Mutations in Cancer) database and website. Br J Cancer 91: 355-358, 2004.

10. Cheng F, McLaughlin PJ, Verderame MF and Zagon IS: Dependence on nuclear localization signals of the opioid growth factor receptor in the regulation of cell proliferation. Exp Biol Med (Maywood) 234: 532-541, 2009.

11. Mayya V, Lundgren DH, Hwang SI, Rezaul K, Wu L, Eng JK, Rodionov V and Han DK: Quantitative phosphoproteomic analysis of $\mathrm{T}$ cell receptor signaling reveals system-wide modulation of protein-protein interactions. Sci Signal 2: ra46, 2009. 
12. Dephoure N, Zhou C, Villén J, Beausoleil SA, Bakalarski CE, Elledge SJ and Gygi SP: A quantitative atlas of mitotic phosphorylation. Proc Natl Acad Sci USA 105: 10762-10767, 2008.

13. Han G, Ye M, Zhou H, Jiang X, Feng S, Jiang X, Tian R, Wan D, Zou $\mathrm{H}$ and $\mathrm{Gu}$ J: Large-scale phosphoproteome analysis of human liver tissue by enrichment and fractionation of phosphopeptides with strong anion exchange chromatography. Proteomics 8 : 1346-1361, 2008.

14. Oppermann FS, Gnad F, Olsen JV, Hornberger R, Greff Z, Kéri G, Mann M and Daub H: Large-scale proteomics analysis of the human kinome. Mol Cell Proteomics 8: 1751-1764, 2009.

15. Olsen JV, Blagoev B, Gnad F, Macek B, Kumar C, Mortensen P and Mann M: Global, in vivo, and site-specific phosphorylation dynamics in signaling networks. Cell 127: 635-648, 2006.
16. Olsen JV, Vermeulen M, Santamaria A, Kumar C, Miller ML, Jensen LJ, Gnad F, Cox J, Jensen TS, Nigg EA, et al: Quantitative phosphoproteomics reveals widespread full phosphorylation site occupancy during mitosis. Sci Signal 3: ra3, 2010.

17. Zanivan S, Gnad F, Wickström SA, Geiger T, Macek B, Cox J, Fässler R and Mann M: Solid tumor proteome and phosphoproteome analysis by high resolution mass spectrometry. J Proteome Res 7: 5314-5326, 2008.

18. Wiśniewski JR, Nagaraj N, Zougman A, Gnad F and Mann M: Brain phosphoproteome obtained by a FASP-based method reveals plasma membrane protein topology. J Proteome Res 9: 3280-3289, 2010. 